\title{
Novel Trench Wiring Formation Process using Photosensitive Insulation Film for Next Generation Packaging
}

\author{
Kenichi Iwashita, Tetsuya Katoh, Akihiro Nakamura, Yasuharu Murakami, and \\ Tomio Iwasaki ${ }^{\dagger}$
}

\author{
Tsukuba Research Laboratory, Hitachi Chemical Co. Ltd.,4-13-1 Hitachi, Ibaraki 317-8555 Japan \\ $\uparrow$ Research and Development Group, Hitachi, Ltd., 7-1-1, Omika, Hitachi, Ibaraki 319-1292, Japan \\ k-iwashita@hitachi-chem.co.jp
}

\begin{abstract}
As there is an increasing demand for advanced electronic devices, high-density and fine circuit is required more than ever before. However, it is difficult to fabricate fine $\mathrm{Cu}$ wiring below $5 \mu \mathrm{m}$ on an organic substrate using current processes such as semi-additive process (SAP). In this paper, the trench wiring formation process with photosensitive organic materials was studied to make fine $\mathrm{Cu}$ wiring below $5 \mu \mathrm{m}$. Photosensitive organic materials were mainly used as protection and insulation layers of very large scale integrated circuit because they simplify via formation processing by photolithography. We newly developed film-type photosensitive insulation material for high-density interposer. The photosensitive insulation film (PIF) showed high resolution $(\mathrm{L} / \mathrm{S}=3 / 3 \mu \mathrm{m}$ for $10 \mu \mathrm{m}$-thick film) and suitability to novel trench $\mathrm{Cu}$ wiring formation process. $\mathrm{Cu}$ embedded wiring $(\mathrm{L} / \mathrm{S}=3 / 3 \mu \mathrm{m}$ for $10 \mu \mathrm{m}$-thick $\mathrm{Cu}$ ) was enabled by trench $\mathrm{Cu}$ wiring formation process.
\end{abstract}

Keywords: photosensitive insulation film, trench wiring formation process, molecular dynamics

\section{Introduction}

Currently, novel electronic devices, such as mobile phones, tablets, and personal computers, have become dramatically smaller and more functionalized. Packaging structures for semiconductors are also required to become smaller and thinner. With the progress of miniaturization in size and advancement in functionality, further scaling down of $\mathrm{Cu}$ wiring and blind via is needed in packaging substrates [1].

Semi-additive process (SAP) method was developed for fine $\mathrm{Cu}$ wiring formation of packaging substrate. In general, electroless $\mathrm{Cu}$ plating applies to $\mathrm{Cu}$ wiring on an insulation layer. However, it is difficult to fabricate $\mathrm{Cu}$ wiring less than $5 \mu \mathrm{m}$, since adhesion strength between the insulation layer and the $\mathrm{Cu}$ wiring becomes low with reducing the contact area.
For fine $\mathrm{Cu}$ wiring formation below $5 \mu \mathrm{m}$, sputtering method $[2,3]$ and trench process [4] were studied. The trench process forms a trench pattern by laser drilling of insulation layer using UV-YAG or excimer laser. Seed layer was deposited on the trench pattern with electroless-plated $\mathrm{Cu}$ and the trench was filled up with electro-plated $\mathrm{Cu}$. However, the laser drilling has difficulties in controlling the shape of fine patterns.

Photosensitive insulation material, such as Polyimides (PI) and Polybenzoxazole (PBO), having great mechanical strength and heat resistance were mainly used as protection and insulation layers of very large scale integrated circuit [5]. The liquid type of photosensitive insulation material has developed for LSI.

We developed the film type of photosensitive insulation material for highdensity interposer. It is phenolic-resin-based 
negative tone resist containing cross-linkers (CL) and photo acid generator (PAG). The photosensitive insulation film (PIF) showed the high resolution $(\mathrm{L} / \mathrm{S}=4 / 4 \mu \mathrm{m}$ and $10 \mu \mathrm{m}$ via for $25 \mu \mathrm{m}$-thick film), high adhesion strength with $\mathrm{Ti} / \mathrm{Cu}$ seed layer and suitability to SAP with sputtering process [6].

In this paper, we studied the dissolution effect of $\mathrm{CL}$ by molecular dynamics simulation and trench wiring formation process with PIF.

\section{Experimental}

2.1. Methods of film sample preparation

The test film samples of PIF were prepared by blending phenol resin $\left(M_{\mathrm{w}}=7,800-15,300\right), \mathrm{CL}$ and PAG, followed by blade casting from methyl ethyl ketone on polyethylene terephthalate (PET) film. The materials were dried at $90{ }^{\circ} \mathrm{C}$ for 10 min to give $10 \mu \mathrm{m}$-thick films.

\subsection{Dissolution ratio}

The samples were laminated on $\mathrm{Si}$ wafers at $100{ }^{\circ} \mathrm{C}$. The laminated wafers were dipped in developer of $2.38 \mathrm{wt} \%$ tetramethyl ammonium hydroxide solution (TMAH) at $23{ }^{\circ} \mathrm{C}$. Dissolution ratio and dissolution ratio was calculated by the following equation.

Dissolution ratio $=$ film thickness/dissolution time (1)

\subsection{Pattern formation}

The laminated wafers were exposed by $i$-line stepper (Canon FPA-3000iw) from 200 to 1000 $\mathrm{mJ} / \mathrm{cm}^{2}$. The exposed wafers were heated on a hot plate at $75^{\circ} \mathrm{C}$ for $8 \mathrm{~min}$ and developed in TMAH at $23{ }^{\circ} \mathrm{C}$.

\subsection{Methods of Molecular Dynamics Simulation}

The diffusion coefficient of polymer was calculated by molecular dynamics simulation. As the initial state, the stabilized matrix of $C L$ in phenol resin was placed in the center, and the stabilized matrix of TMAH in water was placed around the $\mathrm{CL} /$ phenol resin matrix (Figure $1 \mathrm{a}$ ). Then, we calculated the thermal diffusion at $20{ }^{\circ} \mathrm{C}$ (Figure $1 \mathrm{~b}$ ). The diffusion coefficient $\mathrm{D}$ is calculated by using the Einstein equation from $1 \times 10^{-9}$ second position change

$$
\mathrm{D}=<[\text { ri (t)-ri }(0)]^{2}>/ 6 \mathrm{t}
$$

where ri and $t$ are the position coordinate and

time.

(a) Initial state

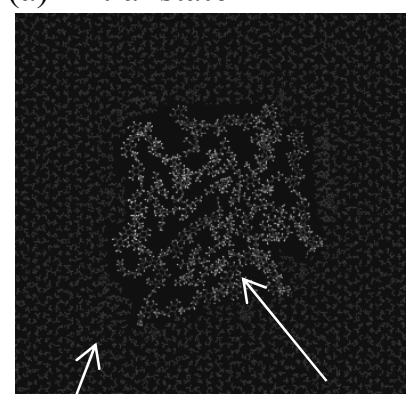

TMAH and $\mathrm{H}_{2} \mathrm{O}$ Phenol resin and CL

Figure 1. Structures used for free energy calculated from molecular dynamics.

The free energy $(\Delta \mathrm{G})$ is also determined by calculating the difference between the total potential energy of the initial state and that of the diffusion state. This equilibration is carried out by using the Newton's equation of motion,

$$
m_{\mathrm{i}} \mathrm{d}^{2} \mathbf{r}_{\mathrm{i}} / \mathrm{d} t^{2}=-\partial U \tau / \partial \mathbf{r}_{\mathrm{i}}
$$

where $m_{\mathrm{i}}, \mathbf{r}_{\mathrm{i}}$, and $U \tau$ are the atomic mass, atomic position of the i-th atom, and total potential energy, respectively.

\subsection{Trench wiring formation process evaluation}

Trench pattern was formed on a $\mathrm{Si}$ wafer by photolithography of the film samples. $\mathrm{Ti} / \mathrm{Cu}$ layer was deposited by sputtering, and $\mathrm{Cu}$ was filled by $\mathrm{Cu}$ electroplating. Then, $\mathrm{Cu}$-embedded wiring in the film sample was formed with chemical mechanical polishing (CMP) (Figure 2).

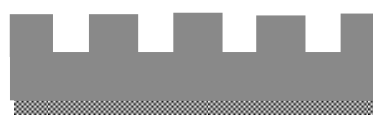

(a) Trench pattern formation

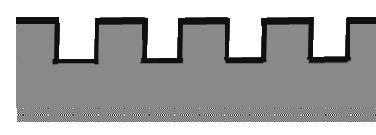

(b) Seed sputtering

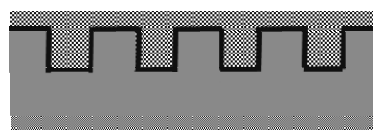

(c) Cu plating

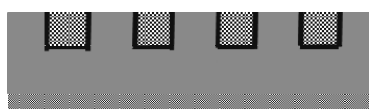

(d) CMP

Figure 2. Process flow of trench wiring formation.

\section{Results and Discussion}

3.1. Effect of CL on dissolution

We found that CLs having low SP and 
multi-functional group enhanced dissolution ratio in unexposed area [6]. To discuss this phenomenon, we calculated the diffusion coefficient of polymer and $\Delta \mathrm{G}$ from molecular dynamics simulation. The results showed that the diffusion coefficient of polymer and $\Delta \mathrm{G}$ increased in the order: mono- $<$ di- $<$ tri- functional CL (Figure 3 and 4). The diffusion coefficient of polymer from molecular dynamics simulation is consistent with that obtained from dissolution ratio evaluation in the last report [6].

$\Delta \mathrm{G}$ of tri- functional CL is larger than that of mono- and di- functional CLs. Tri-functional CL should effectively increase the volume of the polymer and CL. The results suggest that trifunctional $\mathrm{CL}$ suppress the molecular interaction with phenol resin to phenol resin. Therefore, dissolution ratio should be enhanced by rapid penetration of TMAH molecule into phenol resin matrix.

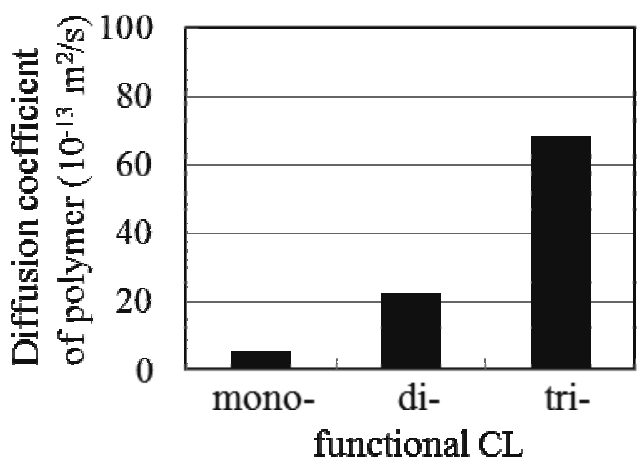

Figure 3. Diffusion coefficient of polymer from molecular dynamics simulation.

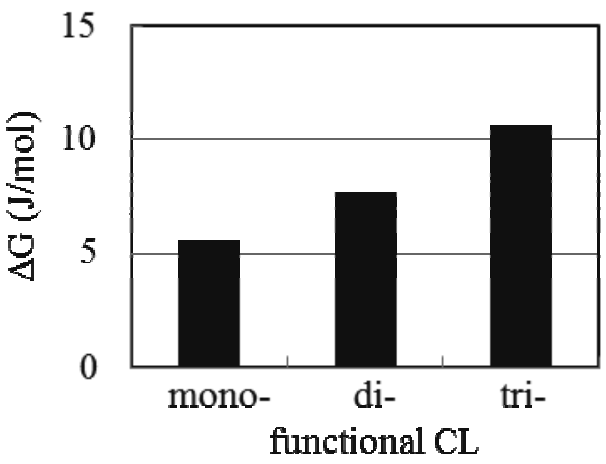

Figure 4. $\Delta \mathrm{G}$ from molecular dynamics simulation

\subsection{Photolithography}

We evaluated the dissolution contrast of the samples which consists of phenol resin, PAG and di- or tri- functional CLs. As shown in Figure 5, tri-functional CL showed the lower dissolution in exposed area, comparing with di-functional CL. The results suggest tri-functional CL effectively reduced the dissolution due to photo-crosslinking. As a result, the sample containing tri-functional CL showed the highest dissolution contrast.

The sample containing tri-functional $\mathrm{CL}$ and additives was subjected to the photolithographic study. The photosensitivity of $10 \mu \mathrm{m}$-thick film was $1000 \mathrm{~mJ} / \mathrm{cm}^{2}$ along with full film retention after TMAH development. As shown in Figure 6, fine line-and-space pattern of $3 \mu \mathrm{m} / 3 \mu \mathrm{m}$ was obtained.

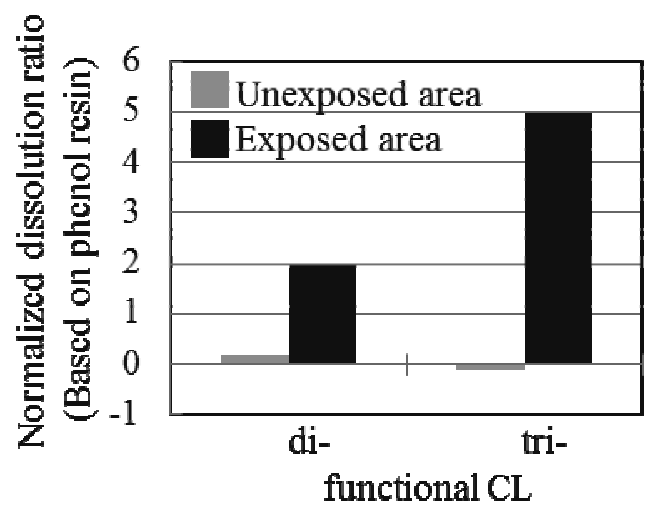

Figure 5. The number of functional groups of $\mathrm{CL}$ versus dissolution ratio of PIF.

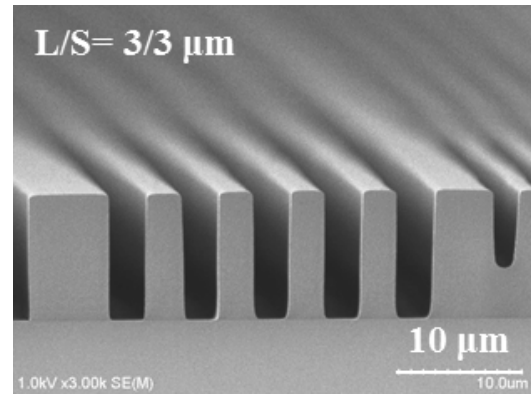

Figure 6. L/S pattern profile of PIF after development. 


\subsection{Trench wiring formation processability}

We demonstrated $\mathrm{Cu}$-embedded wiring in the cured layer of PIF by trench wiring formation process flow. To obtain the trench pattern, we laminated PIF on Si twice. The lower PIF was laminated on $\mathrm{Si}$, exposed with $1000 \mathrm{~mJ} / \mathrm{cm}^{2}$ in whole area without pattern and heated on a hot plate at $75{ }^{\circ} \mathrm{C}$ for $8 \mathrm{~min}$. Then, the upper layer of PIF was laminated on the lower PIF, patterned and cured. The trench pattern was obtained with the upper layer of PIF (Figure 7a). Ti/Cu seed layer was deposited on the trench pattern by sputtering and $\mathrm{Cu}$ was filled up with electro plating. CMP was employed to remove the extra electro plating $\mathrm{Cu}$ and $\mathrm{Ti} / \mathrm{Cu}$ seed layers.

\section{(a) After trench pattern formation}

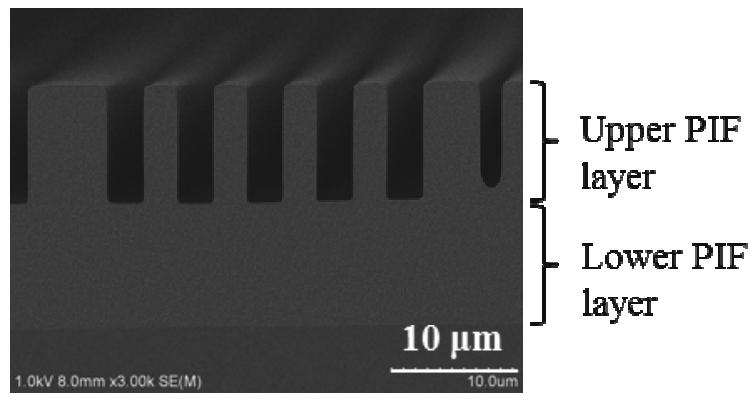

(b) After CMP

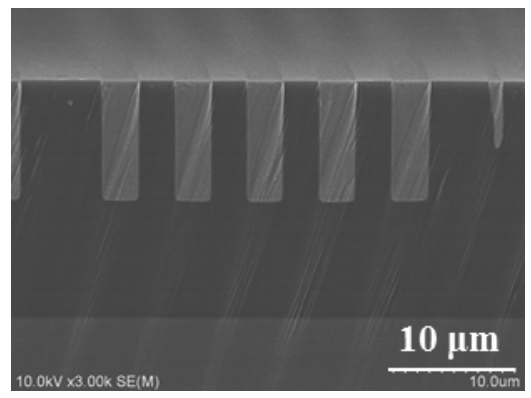

Figure 7. $\mathrm{Cu}$ embedded wiring $(\mathrm{L} / \mathrm{S}=3 / 3 \mu \mathrm{m})$ with PIF by trench wiring formation process flow.

Figure $7 \mathrm{~b}$ showed the trench wiring formation after $\mathrm{CMP}$. The $\mathrm{Cu}$ embedded wiring $(\mathrm{L} / \mathrm{S}=3 / 3$ $\mu \mathrm{m}$ in $10 \mu \mathrm{m}$-thick $\mathrm{Cu}$ ) was fabricated in the cured layer of PIF and did not strip off during
CMP. This shows that PIF has enough adhesion strength with $\mathrm{Ti} / \mathrm{Cu}$. From these results, we concluded that PIF has the processability of the trench wiring formation process.

\section{Conclusion}

We developed the film type of photosensitive insulation materials (PIF). The developed PIF showed the high resolution, and suitability to novel trench $\mathrm{Cu}$ wiring formation process. We believe the developed PIF will be a solution for the high density interposer.

Our findings are:

(1) Tri-functional cross-linker effectively enhances dissolution contrast.

(2) The PIF shows high resolution $(\mathrm{L} / \mathrm{S}=3 / 3 \mu \mathrm{m}$ in $10 \mu \mathrm{m}$-thick film).

(3) The PIF shows the processability to form trench for fine $\mathrm{Cu}$ wiring.

(4) The $\mathrm{Cu}$ embedded wiring $(\mathrm{L} / \mathrm{S}=3 / 3 \mu \mathrm{m}, \mathrm{Cu}$ thickness $=10 \mu \mathrm{m}$ ) could be formed by trench $\mathrm{Cu}$ wiring formation process with PIF.

\section{References}

1. T. Kanki, J. Ikeda, Y. Kobayashi, S. Suda, Y. Nakata and T. Nakamura, IEEE IITC2012, 978-1-4673-1138-0.

2. D-C Hu, P. Lin and Y. H. Chen, Transactions of The Japan Institute of Electronics Packaging, 8 (2015) 18.

3. N. Shimizu, W. Kaneda, H. Arisaka, N. Koizumi S. Sunohara, A. Rokugawa and T. Koyama, IMPAS 2013, Oct.3, TP65, p414.

4. R. Huemoeller, S. Rusli, A. Chiang, Y. Chen, D. Baron, L. Brandt, and B. Roelfts, "UNVEILING THE NEXT GENERATION IN SUBSTRATE TECHNOLOGY" Amkor Technology, Packaging white paper, 2007, 20(1),http://www.amkor.com/go/packagin $\mathrm{g} /$ substrate-technology

5. R. Rubner, Adv Mater., 2 (1990) 452.

6. K. Iwashita, T. Katoh, A. Nakamura, Y. Murakami, T. Iwasaki, Y. Sugimasa, J. Nunoshige and H. Nakano., J. Polym. Sci. Part A: Polym. Chem., 28 (2015) 93. 